\title{
Cone Beam Computed Tomography Evaluation of Root Canal Anatomy in Primary Molars: An in vitro Study
}

\author{
${ }^{1}$ Neelam Joshi, ${ }^{2}$ Anshula Deshpande, ${ }^{3} \mathrm{KS}$ Poonacha, ${ }^{4}$ Seema Bargale, ${ }^{5}$ Kishan Naik, ${ }^{6}$ Dimple Mehta
}

\begin{abstract}
Introduction: Endodontic treatment requires knowledge of root canal morphology and its commonly occurring variation. The utility and relevance of cone beam computed tomography (CBCT) to the practice of endodontics is reported with increasing frequency in the field of endodontics for successful procedures. Therefore, the present study is undertaken to assess the variation in number and morphology of the root canals of primary molars.

Materials and methods: Extracted primary molars with at least two-thirds of intact root, and 7 to $12 \mathrm{~mm}$ length were cleaned in water and stored in $0.5 \%$ sodium hypochlorite for 1 week. Thereafter, the anatomy of the root canals of these primary molars was assessed through CBCT.
\end{abstract}

Results: In the present study, the majority of canals were ribbon shaped. Accessory canals were few and maximum number was found to be present in mesiobuccal root of maxillary first molar and the least in mesiobuccal root of mandibular second molar.

Conclusion: The CBCT proved to be as accurate as the gold standard in studying the presence of accessory canals with clinical applicability. This study highlights the usefulness of CBCT imaging for accurate diagnosis of the unusual canal morphology.

Keywords: Anatomy, Cone beam computed tomography, Primary molars, Pulp dimension, Root canal.

How to cite this article: Joshi N, Deshpande A, Poonacha KS, Bargale S, Naik K, Mehta D. Cone Beam Computed Tomography Evaluation of Root Canal Anatomy in Primary Molars: An in vitro Study. Int J Clin Dent Res 2017;1(1):15-19.

Source of support: Nil

Conflict of interest: None

\section{INTRODUCTION}

Endodontic treatment requires learning of root canal morphology and its usually occurring variations. Sexual orientation, racial source, and geographic area are a portion of the components bringing about variety in root canal anatomy. ${ }^{1}$ Endodontic treatment includes cleaning, shaping, and obturation of the root canal framework. To

\footnotetext{
${ }^{1,5,6}$ Postgraduate Student (3rd Year), ${ }^{2-4}$ Professor

${ }^{1-6}$ Department of Pedodontics and Preventive Dentistry, K M Shah Dental College and Hospital, Sumandeep Vidyapeeth Vadodara, Gujarat, India

Corresponding Author: Anshula Deshpande, Professor Department of Pedodontics and Preventive Dentistry, K M Shah Dental College and Hospital, Sumandeep Vidyapeeth, Vadodara Gujarat, India, e-mail: dranshula@gmail.com
}

enhance successful accomplishment in endodontics, an exhaustive comprehension of the multifaceted nature of the root canal system is key for understanding the principles and issues of cleaning and shaping, for determining the apical limits and dimensions of canal preparations, and for performing successful surgical procedures. ${ }^{2}$ Nattress and Martin, ${ }^{3}$ reported that traditional radiography has issues of superimposition, amplification, and a twodimensional (2D) representation of a three-dimensional (3D) object. Several studies have been directed on permanent teeth to investigate the anatomy of root canals, viz. direct perception with the aid of a microscope ${ }^{4}$ macroscopic sections, ${ }^{5}$ filling of canals with inert material and then decalcification, ${ }^{6}$ and filling of canals and clearing. ${ }^{7}$ However, most of these techniques had serious limitations as most of the relationship of the external structure to the pulp was lost during preparation of samples. These inadequacies have prompted the improvement of 3D procedures.

The advent of 3D imaging has furnished the clinician with expanded understanding of tooth morphology and facilitated interactive image manipulation and enhancement to visualize the area of interest as a 3D volume. ${ }^{8}$ The detection of additional root canals requires a careful clinical and radiographic inspection. Diagnostic tools, such as multiple radiographs, careful examination of the pulpal floor with an endodontic explorer, and better visualization using an operating microscope are all important aids in the detection of additional root canals. Recently, various attempts have been made to use computed tomography (CT) imaging for the confirmatory diagnosis of morphologic aberrations in the endodontic field.

The advancements in the field of radiology have drawn upon the utilization of CT for imaging teeth. The $\mathrm{CT}$ has been extending quickly and cone beam computed tomography (CBCT) is the most recent system, which has been introduced in dentistry since 1991 for imaging hard tissues of the maxillofacial area. There are numerous advantages of this latest system. Firstly, it is an office-based imaging technique, so can be conveniently performed when required; secondly, it procures volumetric information in a single rotation with a short scan time; besides, it produces quality pictures with higher spatial resolution than multislice $\mathrm{CT}$, and to wrap things up, it poses less dangers to patients as a result of the 
reduced radiation dose required. ${ }^{9}$ The $\mathrm{CBCT}$ utility and significance to the act of endodontics is accounted for with expanding recurrence in the field of endodontics. Therefore, the present study is undertaken to assess the variation in number and morphology of the root canals of primary molars. The objectives for the study were:

- To evaluate the distance between roof of pulp chamber and occlusal surface using CBCT.

- To evaluate the distance between floor of pulp chamber and furcation area of tooth using CBCT.

- To evaluate the distance between mesial wall of pulp chamber and mesial surface of tooth using CBCT.

- To evaluate the distance between distal wall of pulp chamber and distal surface of tooth using CBCT.

- To evaluate the number of accessory canals in root canal of primary molars using CBCT.

- To compare and evaluate the shape of root canals through CBCT among maxillary and mandibular molars and first and second primary molars.

\section{MATERIALS AND METHODS}

For the present study, ethical clearance was obtained from the institutional ethical committee (Approval No. SVIEC/ ON/Dent/SRP/15148) of Sumandeep Vidyapeeth. Sample size of 40 extracted primary molars was estimated with 10 maxillary first molar, 10 mandibular first molar, 10 maxillary second molar, and 10 mandibular second molar. Extracted primary molars with at least two-third of intact root and 7 to $12 \mathrm{~mm}$ length were included in the study. Before starting, the teeth were cleaned with soap and washed in running water. Hand scalers were used to remove calculus, if present, on the root surface and stored in $0.5 \%$ sodium hypochlorite for 1 week. Thereafter, the anatomy of the root canals of these primary molars was assessed through CBCT software (Fig. 1). The CBCT facilities were availed from Nidaan Dental Private Limited (Dent-CAT) for the study. The collected data were entered in the master chart prepared on the computer using Microsoft Excel 2007, and the data were analyzed using Statistical Package for the Social Sciences software for descriptive test (standard deviation, coefficient of variation, mean) and independent test. Infection control protocols were followed during the study, and the extracted primary molars were discarded after the completion of study following the infection control protocols.

\section{RESULTS}

\section{Maxillary First Molar}

According to the data (Graph 1), most of the canals in maxillary first molars were ribbon shaped. Also, according to our results, mesiobuccal canal showed variations

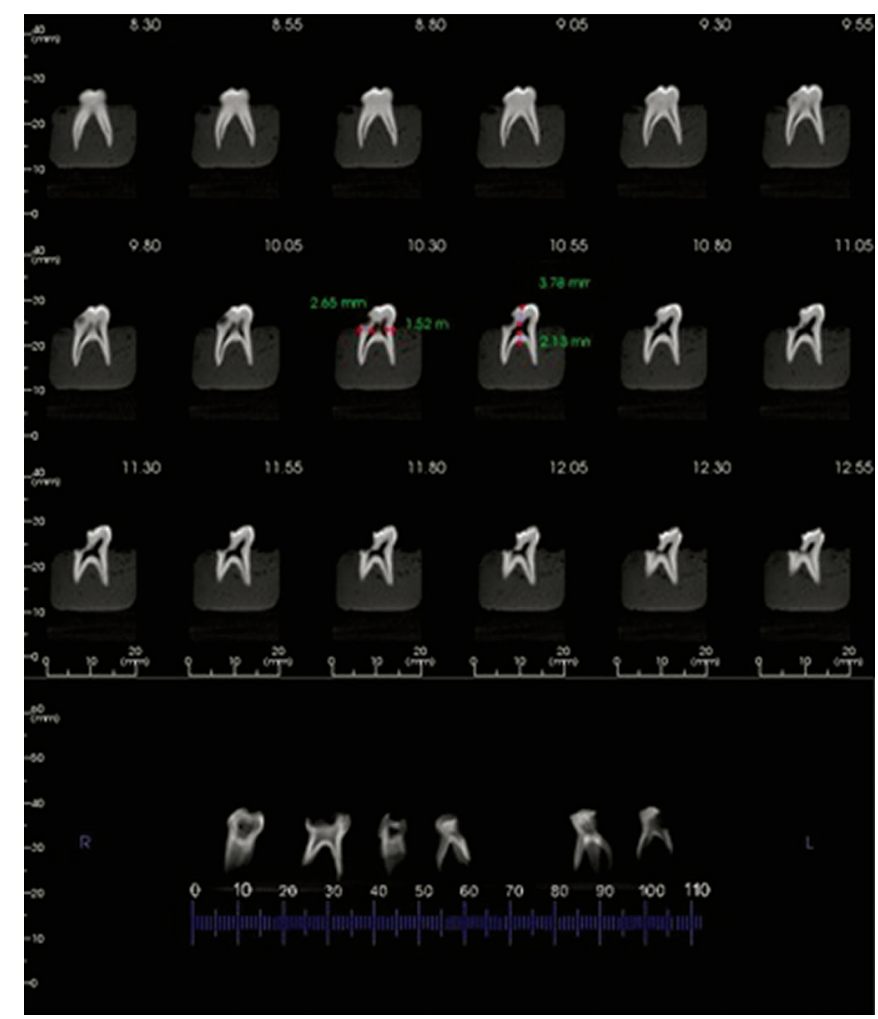

Fig. 1: The СВCT image showing the measure dimensions

in the shape, distobuccal canals were found to be ribbon shaped, and most of the palatal canals were also round in shape.

Observing the pulp dimensions, the distance between occlusal surface and the pulp was $2.90 \mathrm{~mm}$, which was found to be the highest among the remaining tooth. The distance between mesial surface of tooth and pulp was $1.79 \mathrm{~mm}$, distal surface of tooth and pulp was $1.77 \mathrm{~mm}$, and furcation area and pulp was $1.36 \mathrm{~mm}$ (Table 1).

Mesiobuccal canal showed higher frequency of accessory canals as compared with distobuccal, and the least accessory canals were found in palatal canal.

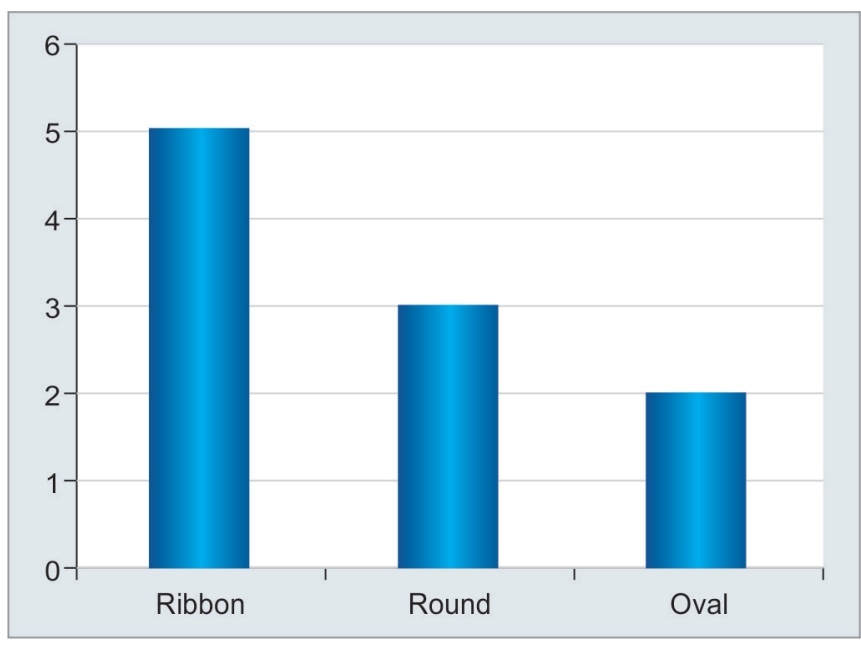

Graph 1: Shape of the canals in maxillary first molar 


\begin{tabular}{llllll}
\hline \multicolumn{6}{c}{ Table 1: Pulp dimensions } \\
\hline Tooth & & Occlusion- & Mesial- & Distal- & Furcation- \\
pum & pulp $(\mathrm{mm})$ & Pulp $(\mathrm{mm})$ & Pulp $(\mathrm{mm})$ \\
\hline Maxillary & Mean & 2.90 & 1.79 & 1.77 & 1.36 \\
$1^{\text {st }}$ molar & SD & 0.37 & 0.42 & 0.38 & 0.27 \\
Maxillary & Mean & 3.01 & 2.18 & 2.18 & 1.25 \\
$2^{\text {nd }}$ molar & SD & 0.24 & 0.20 & 0.21 & 0.10 \\
Mandibular & Mean & 2.62 & 1.47 & 1.46 & 1.27 \\
$1^{\text {st }}$ molar & SD & 0.56 & 0.34 & 0.29 & 0.07 \\
Mandibular & Mean & 2.88 & 1.75 & 1.57 & 1.47 \\
$2^{\text {nd }}$ molar & SD & 0.54 & 0.36 & 0.25 & 0.38 \\
\hline
\end{tabular}

\section{Maxillary Second Molar}

According to the data (Graph 2), the canals were mostly oval in shape. Mesiobuccal and palatal roots showed variations in shape, but distobuccal canal was found to be of round shape.

Observing the pulp dimensions, the distance between occlusal surface and the pulp was $3.01 \mathrm{~mm}$. The distance between mesial surface of tooth and pulp was $2.18 \mathrm{~mm}$,

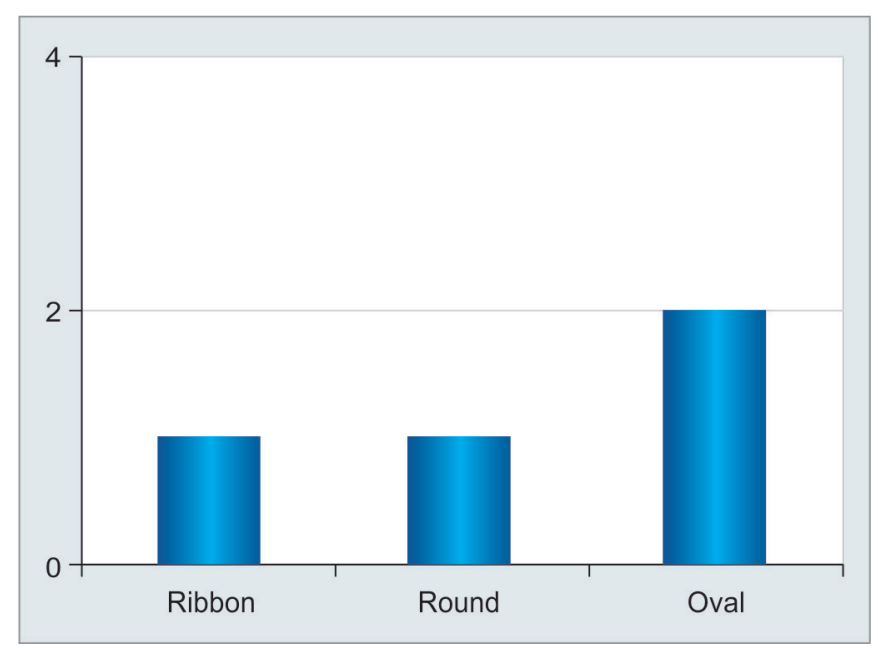

Graph 2: Shape of the canals in maxillary second molar

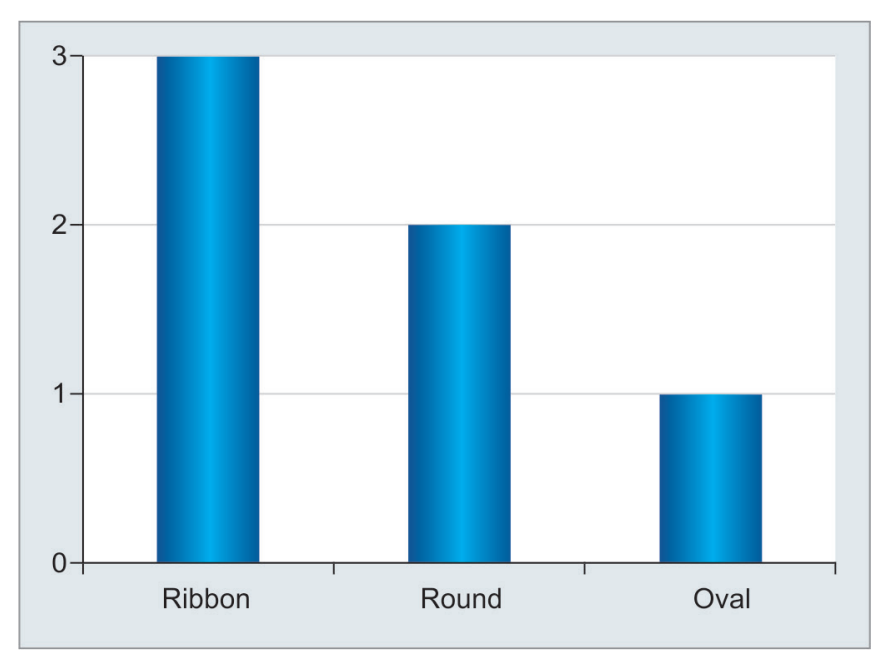

Graph 3: Shape of the canals in mandibular first molar distal surface of tooth and pulp was $2.18 \mathrm{~mm}$, and furcation area and pulp was $1.25 \mathrm{~mm}$.

The maxillary second molar showed higher occurrence of accessory canals. Furthermore, palatal showed the highest occurrence among the three canals of maxillary second molars.

\section{Mandibular First Molar}

According to the data (Graph 3), the canals were mostly ribbon in shape. Mesiobuccal and palatal roots showed variations in shape, but distobuccal canal was found to be of round shape.

Observing the pulp dimensions, the distance between occlusal surface and the pulp was $2.62 \mathrm{~mm}$. The distance between mesial surface of tooth and pulp was $1.47 \mathrm{~mm}$, distal surface of tooth and pulp was $1.46 \mathrm{~mm}$, and furcation area and pulp was $1.27 \mathrm{~mm}$.

Mandibular first molar showed lower occurrence of accessory canals. Only one accessory canal was found to be present in mesiobuccal root.

\section{Mandibular Second Molar}

According to the data (Graph 4), the canals were mostly oval in shape. Mesiobuccal roots showed variations in shape, but mesiolingual canal, distobuccal canal, and distolingual canal were found to be of ribbon shape (Table 2).

Observing the pulp dimensions, the distance between occlusal surface and the pulp was $2.88 \mathrm{~mm}$. The distance between mesial surface of tooth and pulp was $1.75 \mathrm{~mm}$, distal surface of tooth and pulp was $1.57 \mathrm{~mm}$, and furcation area and pulp was $1.47 \mathrm{~mm}$.

Mandibular second molar showed higher occurrence of accessory canals. Mesiobuccal canal was found to have more accessory canals relatively (Table 3).

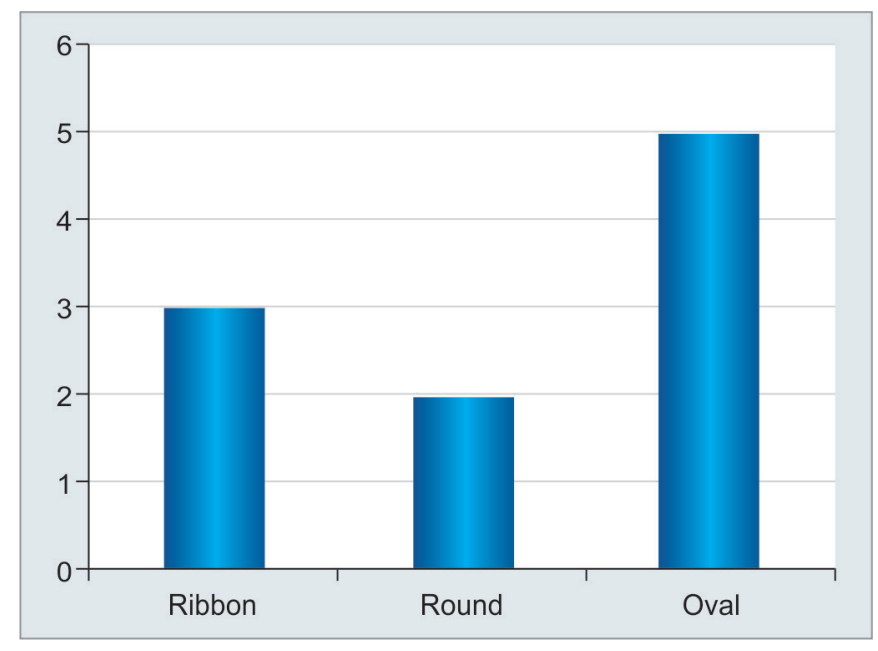

Graph 4: Shape of the canals in mandibular second molar 


\begin{tabular}{|c|c|c|c|c|c|c|}
\hline & Canal & $\begin{array}{l}\text { Mesio- } \\
\text { Buccal }\end{array}$ & $\begin{array}{l}\text { Mesio- } \\
\text { Lingual }\end{array}$ & $\begin{array}{l}\text { Disto- } \\
\text { Buccal }\end{array}$ & $\begin{array}{l}\text { Disto- } \\
\text { Lingual }\end{array}$ & $\begin{array}{l}\text { Palatal/ } \\
\text { Distal }\end{array}$ \\
\hline \multirow{3}{*}{$\begin{array}{l}\text { Maxillary } \\
1^{\text {st }} \text { molar }\end{array}$} & Round & 3 & 0 & 1 & 0 & 7 \\
\hline & Ribbon & 5 & 0 & 10 & 0 & 4 \\
\hline & Oval & 3 & 0 & 0 & 0 & 0 \\
\hline \multirow{3}{*}{$\begin{array}{l}\text { Maxillary } \\
2^{\text {nd }} \text { molar }\end{array}$} & Round & 1 & 0 & 0 & 0 & 1 \\
\hline & Ribbon & 1 & 0 & 3 & 0 & 1 \\
\hline & Oval & 1 & 0 & 0 & 0 & 1 \\
\hline \multirow{3}{*}{$\begin{array}{l}\text { Mandibular } \\
1^{\text {st }} \text { molar }\end{array}$} & Round & 2 & 1 & 0 & 0 & 5 \\
\hline & Ribbon & 3 & 5 & 0 & 0 & 1 \\
\hline & Oval & 1 & 0 & 0 & 0 & 0 \\
\hline \multirow{3}{*}{$\begin{array}{l}\text { Mandibular } \\
2^{\text {nd }} \text { molar }\end{array}$} & Round & 2 & 1 & 0 & 0 & 1 \\
\hline & Ribbon & 3 & 9 & 9 & 9 & 0 \\
\hline & Oval & 5 & 0 & 0 & 0 & 0 \\
\hline
\end{tabular}

\section{DISCUSSION}

Dental pulp is a soft gelatinous, living, cellular tissue of ectomesenchymal origin having various functions and is enclosed within bilayered mineralized structures of enamel, dentin, and/or cementum. Radicular pulp canal is like a wide tube, which extends from the cervical region to apical region of tooth. Hertwig's epithelial root sheath initiates formation of size, shape, and number of the radicular pulp. Pulp canals are much larger in deciduous teeth due to thinner layers of enamel and dentin, and there is no clear demarcation between pulp chamber and root canals. The pulp canals are more slender, tapering, and longer in proportion to the crown. Multirooted teeth show greater degree of interconnecting branches between pulp canals and the pulp; which is normally seen in deciduous teeth. ${ }^{10,11}$

Knowledge regarding the anatomy of primary molars is of utmost importance for various reasons. The distance between roof of pulp chamber and occlusal surface helps and guides us to prevent the perforation of floor of the tooth. For beginners, it is helpful to mark the depth of penetration on the bur itself for prevention of the perforation or removal of larger amount of the unaffected tooth surface.

Similarly, distance between the mesial wall of pulp chamber and mesial surface of tooth helps us for treatment plan, especially the lesions on the proximal surface of the tooth as proximal caries is common in primary molars. Clinicians can have good decision-making in such lesions where the chances of pulp involvement are high. If the operator has knowledge about this anatomy, he/she can have a better treatment output.

Previous studies on root canal anatomy used demineralizing and injecting a dye technique, which produced irreversible changes to the experimental sample. Few researchers have used radiographs to assess root canal morphology, but their accuracy is limited as they construct a 2D image of a 3D object and this can lead to superimposition of the root canals. ${ }^{11}$
Table 3: Number of accessory canals and their

frequency of occurrence

\begin{tabular}{|c|c|c|c|}
\hline Tooth & Type of canal & $\begin{array}{l}\text { No. of } \\
\text { accessory } \\
\text { canal }\end{array}$ & Frequency \\
\hline \multirow{7}{*}{$\begin{array}{l}\text { Maxillary } \\
1^{\text {st }} \text { Molar }(n=33)\end{array}$} & \multirow[t]{3}{*}{ Mesiobuccal (11) } & 0 & 3 \\
\hline & & 1 & 5 \\
\hline & & 2 & 3 \\
\hline & \multirow[t]{2}{*}{ Distobuccal (11) } & 0 & 7 \\
\hline & & 1 & 4 \\
\hline & \multirow[t]{2}{*}{ Palatal (11) } & 0 & 9 \\
\hline & & 1 & 2 \\
\hline \multirow{5}{*}{$\begin{array}{l}\text { Maxillary } \\
2^{\text {nd }} \text { Molar }(n=9)\end{array}$} & \multirow[t]{2}{*}{ Mesiobuccal (3) } & 1 & 2 \\
\hline & & 2 & 1 \\
\hline & \multirow[t]{2}{*}{ Distobuccal (3) } & 0 & 1 \\
\hline & & 1 & 2 \\
\hline & Palatal (3) & 0 & 3 \\
\hline \multirow{5}{*}{$\begin{array}{l}\text { Mandibular } \\
1^{\text {st }} \text { Molar }(n=18)\end{array}$} & \multirow[t]{3}{*}{ Mesiobuccal (6) } & 0 & 4 \\
\hline & & 1 & 1 \\
\hline & & 2 & 1 \\
\hline & Mesiolingual (6) & 0 & 6 \\
\hline & Distal (6) & 0 & 6 \\
\hline \multirow{11}{*}{$\begin{array}{l}\text { Mandibular } \\
2^{\text {nd }} \text { Molar }(n=39)\end{array}$} & \multirow[t]{3}{*}{ Mesiobuccal (10) } & 0 & 5 \\
\hline & & 1 & 4 \\
\hline & & 2 & 2 \\
\hline & \multirow[t]{3}{*}{ Mesiolingual (10) } & 0 & 8 \\
\hline & & 1 & 1 \\
\hline & & 2 & 1 \\
\hline & \multirow[t]{2}{*}{ Distobuccal (9) } & 0 & 7 \\
\hline & & 1 & 2 \\
\hline & \multirow[t]{2}{*}{ Distolingual (9) } & 0 & 8 \\
\hline & & 1 & 1 \\
\hline & Distal (1) & 0 & 1 \\
\hline
\end{tabular}

Till date, many techniques have been used for studying the canal anatomy, an ideal technique would be one that is precise, easy, nondestructive, and, most importantly, feasible in the in vivo scenario. Although canal staining and tooth clearing are generally considered the gold standard in these studies, they have limited clinical applicability. However, digital radiography can be used in vivo, but was proved to be significantly less accurate than decalcification and sectioning by Zheng et al. ${ }^{12}$

The CBCT has been used successfully in endodontics for the diagnosis of endodontic pathosis and canal morphology, assessment of pathosis of nonendodontic origin, evaluation of root fractures and trauma, analysis of external and internal root resorption, invasive cervical resorption, and presurgical planning. ${ }^{13,14}$ It has been shown that the rarer the aberration, the more likely it is to be bilateral in occurrence. ${ }^{15}$ In the present case, CBCT was used for better understanding of the complex root canal anatomy. It is a noninvasive, $3 \mathrm{D}$ imaging technique, which can be used in vivo. ${ }^{16}$

The results of this study were quite similar to those of previous studies, and CBCT proved to be as accurate as 
the gold standard in studying the presence of accessory canals with clinical applicability. ${ }^{17}$ In the present study, all primary maxillary and mandibular molars had variations in pulp morphology. Similar observations were found by Edwin and Cohen. ${ }^{18,19}$ Presence of accessory root canals in primary molars was confirmed by Simpson, Skillen, and Winter. ${ }^{20-22}$

Since radiographs are superimpositions of overlying structures, which may obscure the structure of interest and might not represent the actual morphology, it is unlikely that radiographs show complexities of the root canal morphology, and they cannot be utilized to detect multiple canals or lateral canals. ${ }^{21-24}$ Therefore, there are impediments in the value of radiographs alone in depicting certain aspects of root canal morphology. ${ }^{23}$ In contrast with conventional dental radiographs, 3D images of primary molars might give better insights and knowledge of variations in the root canal morphology, which would enhance dentists' interpretative capability for correct diagnoses. 3,25,26

\section{CONCLUSION}

Endodontic treatment is essentially directed toward the prevention and control of pulpal and periradicular infections. However, the success of endodontic therapy depends on the knowledge of root canal anatomy. The present study reveals that CBCT can be considered to be an advancement over the existing techniques, with accuracy similar to the gold standards in studying and clinical applicability. Treating additional aberrant canals can be challenging, but the inability to find root canals may cause failures. The evaluation of CBCT images can result in better understanding of root canal anatomy, which enables the clinician to investigate the root canal system and to clean, shape, and obturate it more efficiently.

\section{REFERENCES}

1. Sandhya R, Velmurugan N, Kandaswamy D. Assessment of root canal morphology of mandibular first premolars in the Indian population using spiral computed tomography: an in vitro study. Indian J Dent Res 2010 Apr-Jun;21(2):169-173.

2. Zoremchhingi, Joseph T, Varma B, Mungara J. A study of root canal morphology of human primary molars using computerised tomography: an in vitro study. J Indian Soc Pedod Prev Dent 2005 Mar;23(1):7-12.

3. Nattress BR, Martin DM. Predictability of radiographic diagnosis of variations in root canal anatomy in mandibular incisor and premolar teeth. Int Endod J 1991 Mar;24(2):58-62.

4. Sempira HN, Hartwell GR. Frequency of second mesiobuccal canals in maxillary molars as determined by use of an operating microscope: a clinical study. J Endod 2000 Nov;26(11):673-674.

5. Salama FS, Anderson RW, McKnight-Hanes C, Barenie JT, Myers DR. Anatomy of primary incisor and molar root canals. Pediatr Dent 1992 Mar-Apr;14(2):117-118.
6. Rosenthiel E. Transparent model teeth with pulp. Dent Dig 1957;63:154.

7. Ayhan H, Alacam A, Olmez A. Apical microleakage of primary teeth root canal filling materials by clearing technique. J Clin Pediatr Dent 1996 Winter;20(2):113-117.

8. Gava MM. What the general practitioner should know about cone beam computed tomography technology. Oral Health Dent Manag 2009;8:14-21.

9. Chow BK, Chow JK. Applications of office based three dimensional technologies including cone beam computed tomography and rapid prototyping in the management of maxillofacial trauma Literature review and a case report. Hong Kong Dent J 2009;6:93-97.

10. Bhaskar, SN. Orban's oral histology and embryology. 11th ed. Mosby Year Book; 1991.

11. Ford, PP. Harty's endodontics in clinical practice. 4th ed. Wright; 1997.

12. Zheng QH, Wang $Y$, Zhou XD, Wang Q, Zheng GN, Huang DM. A cone-beam computed tomography study of maxillary first permanent molar root and canal morphology in a Chinese population. J Endod 2010 Sep;36(9):1480-1484.

13. Cotton TP, Geisler TM, Holden DT, Schwartz SA, Schindler WG. Endodontic applications of cone-beam volumetric tomography. J Endod 2007 Sep;33(9):1121-1132.

14. Tyndall DA, Rathore S. Cone-beam CT diagnostic applications: caries, periodontal bone assessment, and endodontic applications. Dent Clin North Am 2008 Oct;52(4):825-841.

15. Sabala CL, Benenati FW, Neas BR. Bilateral root or root canal aberrations in a dental school patient population. J Endod 1994 Jan;20(1):38-42.

16. Vertucci FJ, Anthony RL. A scanning electron microscopic investigation of accessory foramina in the furcation and pulp chamber floor of molar teeth. Oral Surg Oral Med Oral Pathol 1986 Sep;62(3):319-326.

17. Haznedaroğlu F, Ersev H, Odabaşi H, Yetkin G, Batur B, Aşçi S, Işsever H. Incidence of patent furcal accessory canals in permanent molars of a Turkish population. Int Endod J 2003 Aug;36(8):515-519.

18. Edwin D, Hibbard ED, Ralph L. Morphology of root canal of the primary molar teeth. J Dent Child 1957;24:250.

19. Cohen, S.; Burns, RC. Pathways of pulp. 6thed. Mosby Year Book; 1994. p. 652.

20. Simpson WJ. An examination of root canal anatomy of primary teeth. J Can Dent Assoc (Tor) 1973 Sep;36(9):637-640.

21. Skillen WG. Morphology of the root canal. JADA 1932;19:5, 719-735.

22. Winter GB. Abscess formation in connection with deciduous molar teeth. Arch Oral Biol 1962 May-Jun;7:373-379.

23. Zurcher, E. The anatomy of the root canals of the teeth of the deciduous dentition and of the first permanent molar. New York: William Wood and Co.; 1925.

24. Wiiddowson, TW. Special orodental anatomy and physiology and dental histology, human and comparative. 7th ed. Vol. 1. Stapless Boss Ltd.

25. Barker BC, Parsons KC, Williams GL, Mills PR. Anatomy of root canals. IV: deciduous teeth. Aust Dent J 1975 Apr;20(2):101-106.

26. Omer OE, Al Shalabi RM, Jennings M, Glennon J, Claffey NM. A comparison between clearing and radiographic techniques in the study of the root-canal anatomy of maxillary first and second molars. Int Endod J 2004 May;37(5):291-296. 